\title{
Detection of Multidrug Resistant and Shiga Toxin Producing Escherichia coli (STEC) From Apparently Healthy Broilers in Jessore, Bangladesh
}

\author{
Jasmin Akter Runa ${ }^{1}$, Mohammed Bakhtiar Lijon ${ }^{2, ~ *, ~ M o h a m m e d ~ A b d u r ~ R a h m a n ² ~}$ \\ ${ }^{1}$ Department of Microbiology, Jessore Science and Technology University, Jessore, Bangladesh \\ ${ }^{2}$ Microbiology Laboratory, Modern Food Testing Laboratory, Chittagong City, Bangladesh \\ Email address: \\ runajasmin2@gmail.com (J. A. Runa), lijonmicro2014@gmail.com (M. B. Lijon), raihan07sust@gmail.com (M. A. Rahman) \\ ${ }^{*}$ Corresponding author
}

To cite this article:

Jasmin Akter Runa, Mohammed Bakhtiar Lijon, Mohammed Abdur Rahman. Detection of Multidrug Resistant and Shiga Toxin Producing Escherichia coli (STEC) From Apparently Healthy Broilers in Jessore, Bangladesh. Frontiers in Environmental Microbiology.

Vol. 4, No. 1, 2018, pp. 16-21. doi: 10.11648/j.fem.20180401.13

Received: December 26, 2017; Accepted: January 19, 2018; Published: February 2, 2018

\begin{abstract}
The research work was undertaken for detection and determination of antibiogram profile of Escherichia coli (E. coli) that produce Shiga toxin from apparently healthy broilers $(\mathrm{n}=8)$ from different commercial farms of Jessore, Bangladesh. Broiler cloacal swabs $(\mathrm{n}=8)$ were collected by inserting the sterile swab stick in the cloacae of broiler and inoculated into peptone water for enrichment for 24 hours at $37^{\circ} \mathrm{C}$. Enriched culture was streaked onto Eosin Methylene Blue (EMB) agar for isolation of pure bacterial culture. Then pure bacterial culture was streaked onto Mac-Conkey (MC) agar to identify Gram negative bacteria. Cultural method, Gram staining, biochemical reaction and polymerase chain reaction technique were used to identify the bacteria. The antibiogram profiles of bacteria were investigated against 6 commonly used antibiotics (Ciprofloxacin, Ampicillin, Colistinsulphate, Erythromycin, Neomycin and Penicillin) by disc diffusion method. Five E. coli isolates were identified and Shiga toxin producing E. coli (STEC) was detected by amplifying 372-bp fragment of Stx2 gene in polymerase chain reaction (PCR) assay. The prevalence of the Shiga toxin generating E. coli (STEC) in broiler cloacal swab was $62.5 \%$. All isolates $(100 \%)$ were resistant to Ampicillin, Colistinsulphate, Erythromycin, Neomycin and Penicillin and sensitive to Ciprofloxacin. The findings of this research strongly imply that broiler harbor multidrug resistant and Shiga toxin producing E. coli (STEC) which may cause public health problem if enter into human food chain.
\end{abstract}

Keywords: Antibiogram, Escherichia coli, PCR Assay, Prevalence, Shiga Toxin

\section{Introduction}

E. coli is a gram-negative, rod-shaped and facultative anaerobic bacterium belongs to Enterobacteriaceae family [1] commonly found in gastrointestinal tract of human and animals including poultry [2]. It is pathogenic to both human and poultry [3] to some extent although it helps to hinder colonization of pathogenic bacteria in the intestine [4], aids in digestion and can benefit their hosts by producing small amounts of vitamins $\mathrm{B}_{12}$ and $\mathrm{K}_{2}$. Most isolates of $E$. coli are nonpathogenic but existence of this bacterium provides evidence of faecal contamination of food. Coliforms are pathogenic and opportunistic serotypes that found in intestine around $10-15 \%$. It causes a variety of lesions in immune compromised hosts along with poultry [5]. Some serogroups of E. coli generally classified into six subgroups including enterotoxigenic E. coli (ETEC), enteropathogenic E. coli (EPEC), enteroinvasive E. coli, enterhemorrhagic E. coli (EHEC), enteroadherent E. coli and diffusely adherent $E$. coli [6]cause disease and food poisonings. The EHEC strains are one of subset of Shiga toxin (Stx) producing E. coli (STEC) strains which is isolated from patients [7]. STEC has recently been found from broiler in Bangladesh [8]. Food contaminated with 
STEC strains is the main cause of human infections [9]. STEC are responsible for severe clinical symptoms such as hemorrhagic colitis (HC) and the potentially lethal hemolytic uremic syndrome (HUS) [10]. E. coli having Shiga toxin is distinguished by the production of Cytotoxin that break up protein synthesis with in host cells. For their activity on Vero cells these toxins are called Verocytotoxins. In Bangladesh misused of antibiotic has been extensively increased either to promote the growth or to control infectious disease of poultry. Emergences of multi-drug resistant $E$. coli are continuously increasing because of the greater abuse of antibiotic [11]. Antibiotic may be the guide to the appearance and transmission of resistant E. coli that can pass into people through food or direct contact with infected animals. These resistant organisms may play a vital role in the dissemination of antimicrobial resistance to human pathogens [12]. Aims of the research work were (i) isolation, identification and detection of Shiga toxin generating E. coli (STEC) from broiler and (ii) determination of antibiogram profile of Shiga toxin generating E. coli (STEC) against six commonly used antibiotics.

\section{Materials and Methods}

\subsection{Collection of Sample}

A total of 8broiler samples were collected from different commercial farms at Jessore, Bangladesh in Period of January to June, 2013. The samples were transported to Department of Microbiology, Jessore Science and Technology University (JSTU) for bacteriological study.

\subsection{Processing and Enrichment of Samples}

The sterile swab sticks was inserted into the cloacae of the broilers and placed in $5 \mathrm{ml}$ peptone water. Samples were mixed well by vortex mixer machine separately and resulting solution was then incubated at $37^{\circ} \mathrm{C}$ overnight for enrichment.

\subsection{Isolation of Bacteria}

One loopfull of enrichment culture of cloacal swab was separately streaked duplicate onto selective media for $E$. coli such as Eosin Methylene Blue (EMB) agar that was incubated aerobically at $37^{\circ} \mathrm{C}$ for 24 hours. When all plate shown monotypeof colony distinctly, it was considered as pure. To purify the isolates repeated streaking onto EMB agar plates were carried out. Pure bacterial culture streaked onto differential media such as Mac-Conkey agar (MC) to differentiate between gram negative and gram positive bacteria. Finally 5 well-spaced colonies were selected for further study according to their cultural and morphological characteristics.

\subsection{Identification of Bacteria}

On the basis of cultural characteristics and colony morphology on the EMB agar and MC agar bacteria were identified. Gram's staining method [13], Motility test [14], Sugar fermentation test [15] and biochemical tests such as: Oxidase test [16], Catalase test [17], Citrate utilization test [16], Indole test [15], Voges-Proskauer (VP) test [18] and Methyl red reaction [18] were carried out for bacterial identification.

\subsection{Molecular Detection of Bacteria}

A genus specific PCR method was conducted to identify Shiga toxin generating E. coli (STEC) by amplifying 372-bp fragment of Stx2 gene using previously published primers [19].

\subsection{Antibiotic Sensitivity Test}

Five isolates were tested for antimicrobial drug susceptibility against six different antibiotics such as: Ciprofloxacin, Ampicillin, Colistinsulphate, Erythromycin, Penicillinand Neomycin (Himedia, India). The antibiotics sensitivity test was performed according to instructions of the Clinical and Laboratory Standard Institute (CLSI) [20].

\section{Results and Discussion}

\subsection{Isolation of E. coli}

Colony characteristics of $E$. coli observed in EMB and MC agar and found green metallic sheen colony in EMB agar and rose pink lactose fermented colony in MC agar (Figure 1). Similar Colonial feature were reported by [21, 22]. In Gram's staining isolated bacteria were found Gram negative short rod in single or paired arranged (Figure 2) which was supported by several authors [21-23].

Table 1. Prevalence of E. coli in broiler.

\begin{tabular}{lllll}
\hline Name of Samples & Number of samples tested & $\begin{array}{l}\text { Number of culture positive } \\
\text { samples }\end{array}$ & $\begin{array}{l}\text { Number of PCR positive } \\
\text { samples }\end{array}$ & $\begin{array}{l}\text { Prevalence (\%) of } \boldsymbol{E} \text {. coli of } \\
\text { the study }\end{array}$ \\
\hline Broiler cloacal swabs & 8 & 5 & 5 & 62.5 \\
\hline
\end{tabular}




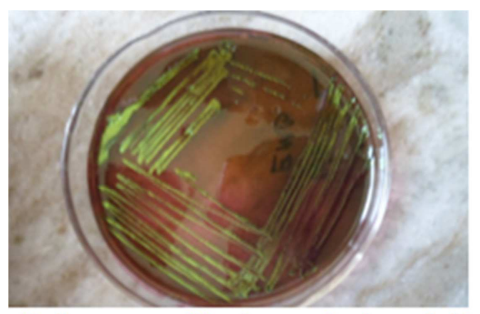

(I) Green-metallic sheen colonies of $E$. colion EMB agar.

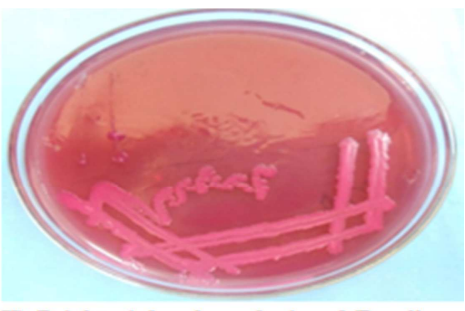

(II) Bright pink color colonies of $E$. coli on Mac-Conkey (MC) agar.

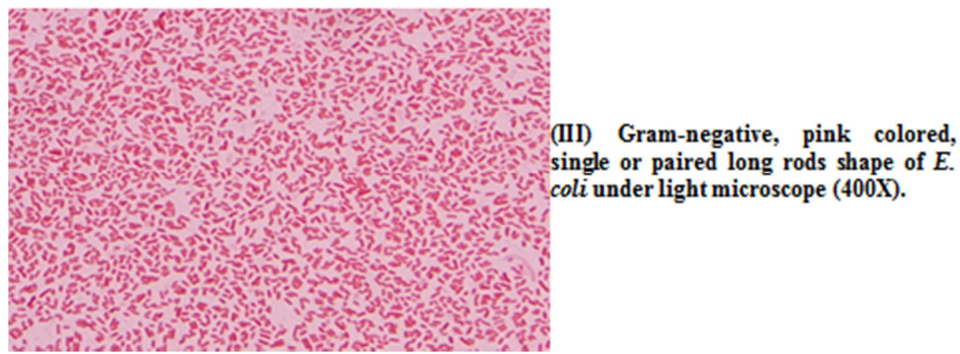

Figure 1. Cultural properties of E. coli on EMB (I) and MC (II) agar and Gram's staining characteristics of E. coli under light microscope (III).

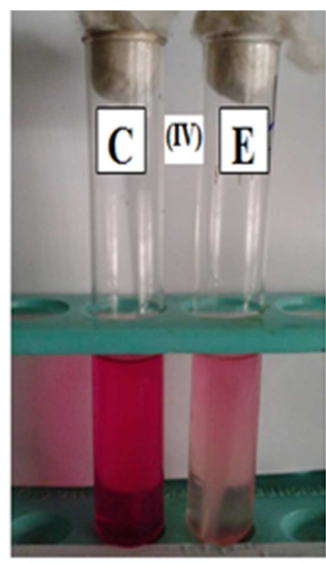

(IV) Diffused growth ertending aray from stab inoculating line indicated motility (E) of $E$. coli and no diffused grovth indicated non-motility of $E$. coli in control (C).

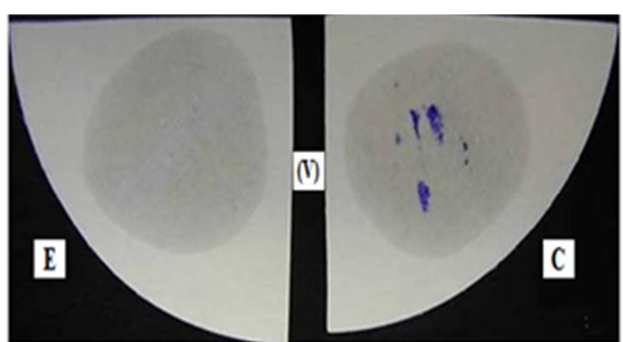

(V) Oridase negatire test of $E$. colli is indicated by absence of coloration (I) and positire test by an intense detp purple hue in control (C).

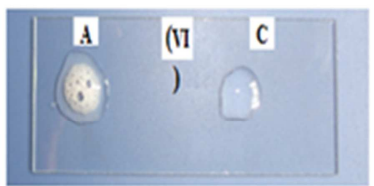

(Vi) Catalase positire test of $E$. coli is indicated by bubble formation $(A)$ and negative test by no bubble formation in control $(C)$.

Figure 2. Motility (IV), Oxidase (V) and Catalase (VI) test results of E. coli.

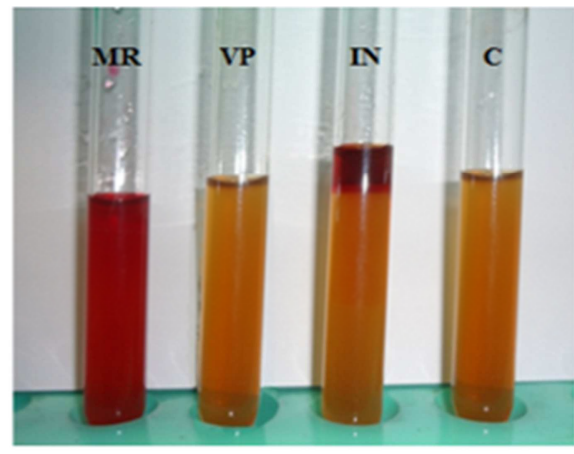

(VII)

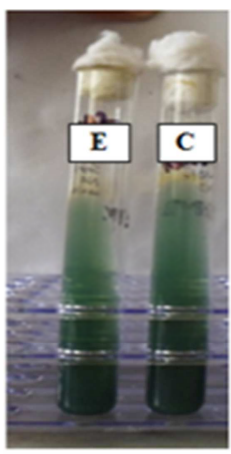

(VIII)
Figure 3. Results of IMViC tests of E. coli. (VII) Development of red color of the broth indicates the positive Methyl red test (MR), No change of color of the broth indicates negative Voges-Proskauer test (VP), red color band at the junction of broth indicates the positive Indole test (IN), No change of color of the control broth (C). (VIII) No change of green color of the citrate medium to blue color indicates negative Citrate test (E) and no change of color of medium in control (C).

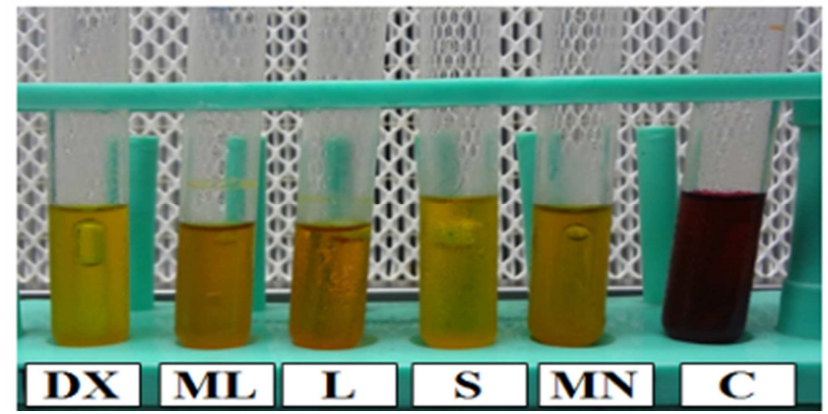

Figure 4. Results of sugar fermentation tests of E. coli. E. coli fermented dextrose $(D X)$, maltose $(M L)$, lactose $(L)$, sucrose $(S)$ and mannitol $(M N)$ with the production of both acid and gas. No change of color of sugar broth in control $(C)$.

\subsection{Identification of E. coli}

All the isolates of $E$. coli were exhibited the motile feature in MIU media (Figure 2). Motile feature of E. coli in MIU 
media wasdescribed by the authors [24]. The isolates revealed negative reaction on Oxidase test and positive reaction on Catalase test (Figure 2). Negative Oxidase test and positive Catalase testresults were also reported by other authors $[23,25]$ in their research work. The isolates exhibited positive reaction in Indole test, Methyl Red test and Citrate test but negative reaction in Voges-Proskauer test (Figure 3) which were reported by many authors[21-23, 25]. In this study, the isolates of $E$. coli were found to ferment the five basic sugars with the production of both acid and gas (Figure 4). Similar sugar fermentation test results were reported by several authors $[21,22,25]$. Results of sugar fermentation, motility and biochemical testsare summarizes in the Table (2).

Table 2. Summary of sugar fermentation, motility and biochemical test results for E. coli.

\begin{tabular}{|c|c|c|c|c|c|}
\hline \multirow{2}{*}{ Name of tests } & \multirow{2}{*}{$\begin{array}{l}\text { Results of } \\
\text { this study }\end{array}$} & \multirow{2}{*}{$\begin{array}{l}\text { Results of Bergey's } \\
\text { Manual** }\end{array}$} & \multicolumn{2}{|c|}{ Results of other investigators } & \multirow{2}{*}{ Interpretation } \\
\hline & & & Results & References & \\
\hline \multicolumn{5}{|c|}{ 1. Sugar fermentation tests profiles using } & \multirow{14}{*}{ Escherichia coli } \\
\hline Dextrose (DX) & $\mathrm{AG}$ & $\mathrm{AG}$ & AG & {$[22]$} & \\
\hline Sucrose (S) & $\mathrm{AG}$ & AG & AG & {$[22]$} & \\
\hline Lactose (L) & $\mathrm{AG}$ & $\mathrm{AG}$ & AG & {$[23]$} & \\
\hline Maltose (ML) & GA & AG & AG & {$[22]$} & \\
\hline Mannitol (MN) & $\mathrm{AG}$ & $\mathrm{AG}$ & $\mathrm{AG}$ & {$[22]$} & \\
\hline 2. Motility test using MIU media & Motile & Motile & Motile & {$[24]$} & \\
\hline 3. Biochemical test & & & & & \\
\hline Oxidase & + & + & + & {$[23]$} & \\
\hline Catalase & + & + & + & {$[23]$} & \\
\hline Citrate & - & - & - & [23] & \\
\hline Indole & + & + & + & [23] & \\
\hline MR & + & + & + & [23] & \\
\hline VP & - & - & - & [23] & \\
\hline
\end{tabular}

Legend: $\mathrm{DX}=$ Dextrose, $\mathrm{ML}=$ Maltose, $\mathrm{L}=$ Lactose, $\mathrm{S}=$ Sucrose, $\mathrm{MN}=$ Mannitol; $\mathrm{AG}=$ Acid and Gas, $+=$ Positive, $-=$ Negative, $* *=\mathrm{Bergey}$ 's Manual of Determinative Bacteriology [25]

\subsection{Detection of Shiga Toxin Producing E. coli (STEC)}

A genus specific PCR method was carried out to screen Shiga toxin generating E. coli from broiler. DNA extracted from green metallic sheen colony grown on EMB agar successfully amplified 372-bp fragment of Stx2 gene confirmed broiler bacterial isolates are E. coli and produced Shiga toxin (Figure 5). Our result of PCR was coincided with the findings of other authors [26, 27]. The amplification of Stx2 gene from broiler represents the pathogenic from of $E$. coli that have public health importance where threat like bloody diarrhea, life-threatening hemolytic-uremic syndrome and hemorrhagic colitis. This evidence supported by [28, 29].

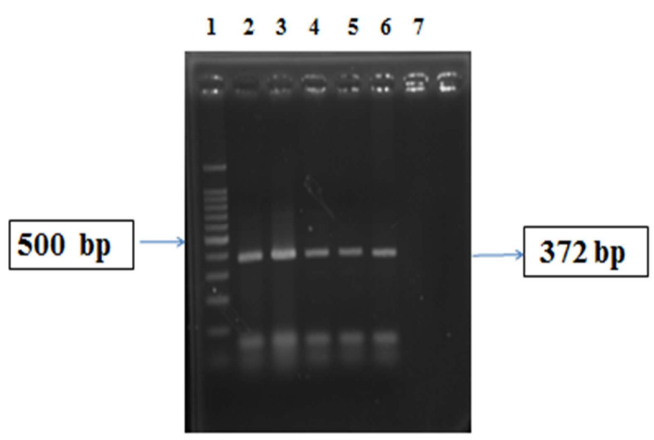

Figure 5. PCR of Stx2 gene of E. coli. Lane 1: $100 \mathrm{bp}$ DNA ladder, Lane 2, 3, 4, 5 and 6: Tested Sample, Positive for Stx2 gene, lane 7: Negative Control.

\subsection{Prevalence of Shiga Toxin Producing E. coli}

Five (n=5) E. coli were isolated, identified and detected from the broiler cloacal swab. The prevalence of $E$. coli in cloacal swab of broiler was $62.5 \%$ (Table 1)which is similar to the findings of the author [30]. 66\% prevalence of $E$. coliwas reported by the author [23] in cloacal swab of broiler which is closed to the present findings. Another researcher [22] also reported $63.6 \%$ prevalence of $E$. coli in broiler.

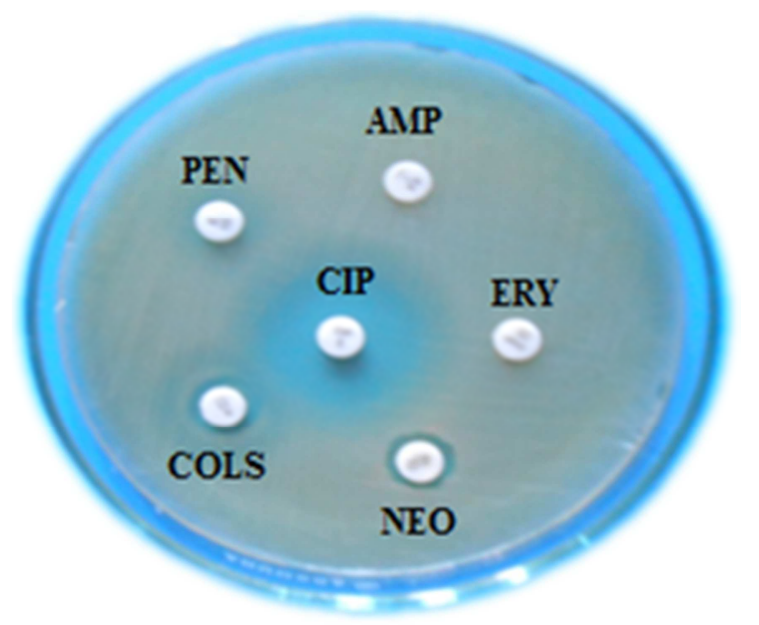

Figure 6. Antibiogram profiles of E. coli against ampicillin (AMP), penicillin (PEN), ciprofloxacin (CIP), erythromycin (ERY), colistinsulphate (COLS) and neomycin (NEO). The isolates were found resistant to ampicillin, penicillin, erythromycin, colistinsulphate and neomycin and sensitive to ciprofloxacin.

\subsection{Antibiogram profile of Shiga Toxin Producing E. coli (STEC)}

On the basis of zone of inhibition E. coli isolates were found sensitive against Ciprofloxacin (CIP) (Figure 6). This finding coincides with the previous result of $[23,31]$. 
Resistance of E. coli was observed against Erythromycin (ERY), Ampicillin (AMP), Neomycin (NEO), Penicillin(PEN) and Colistinsulphate (COLS) and found the entire isolates of broiler to shown resistance properties
(Figure 6). The result was supported by several authors[23, $31,32]$. Reckless use of antibiotics made the organisms resistant against several antibiotics. Antibiogram profiles of STEC shown in Table (3).

Table 3. Summary of antibiogram profiles of E. coli against six commonly used antibiotics.

\begin{tabular}{|c|c|c|c|c|c|c|c|c|c|c|c|c|c|c|c|c|c|c|}
\hline \multirow{3}{*}{ No. of isolates tested } & \multicolumn{18}{|c|}{ Antibiogram profiles of $E$. coli } \\
\hline & \multicolumn{3}{|c|}{ AMP } & \multicolumn{3}{|c|}{ PEN } & \multicolumn{2}{|c|}{ CIP } & \multicolumn{4}{|c|}{ ERY } & \multicolumn{2}{|c|}{ COLS } & \multicolumn{3}{|c|}{ NEO } & \multirow[b]{2}{*}{$\mathbf{S}$} \\
\hline & $\mathbf{R}$ & I & $\mathbf{S}$ & $\mathbf{R}$ & I & $\mathbf{S}$ & $\mathbf{R}$ & I & $\mathbf{S}$ & $\mathbf{R}$ & I & $\mathbf{S}$ & $\mathbf{R}$ & I & $\mathbf{S}$ & $\mathbf{R}$ & I & \\
\hline 5 & 5 & 0 & 0 & 5 & 0 & 0 & 0 & 0 & 5 & 5 & 0 & 0 & 5 & 0 & 0 & 5 & 0 & 0 \\
\hline
\end{tabular}

Legend: AMP: Ampicillin, PEN: Penicillin, CIP: Ciprofloxacin, ERY: Erythromycin, COLS: Colistinsulphate, NEO: Neomycin

\section{Conclusion}

Outcome of this research work indicated that broiler harbors Shiga toxin generating E. coli (STEC). Current study suggest that multidrug resistant $E$. coli is prevalent in broiler of the study area which may cause public health hazard if enter into the food chain. The occurrence of the bacteria should strongly beadvised as deleterious for health and recommended the preventing risk factors. Ciprofloxacin was proved to be the best antibiotics to treat $E$. coli infection as it was highly effective.

\section{Conflict of Interest}

The authors declare that they have no competing interests.

\section{References}

[1] Riley L, Remis R, Helgerson S, McGee H, Wells J, et al. (1983) Hemorrhagic colitis associated with a rare Escherichia coli serotype. N Engl J Med.308 (12): 681-685. doi:10.1056/NEJM198303243081203.

[2] JawetzE, Melnick J, Adelberg EA. Review of Medical Microbiology (1984) $16^{\text {th }}$ ed. Los Altos, California: Long Medical Publication, pp. 122-144.

[3] Levine MM (1987) Escherichia coli that cause diarrhea: enterotoxigenic, enteropathogenic, enteroinvasive, enterohemorrhagic and enteroadherent. J Infect Dis. 155 (3): 377-389.

[4] Hudault S, Guignot J, Servin AL (2001)Escherichia coli strains colonizing the gastrointestinal tract protects germ-free mice against Salmonella typhimurium infection. Gut. 49: 47-55.

[5] Barnes HJ, Gross WB (1997) Colibacillosis, Diseases of Poultry. 10th ed. London, UK: B. W. Calnek, ed. Mosby-Wolf Publication Ltd., pp. 131-139.

[6] Holko I, Bisova T, Holkova Z, Kmet V (2006) Virulence markers of Escherichia coli strains isolated from traditional cheeses made from unpasteurized sheep milk in Slovakia. Food Control. 17: 393-396.

[7] Karmail MA, Gannon V, Sargeant JM (2009) Vero-Cytotoxin producing Escherichia coli (VTEC). Vet Microbiol. 140: 360370. doi:10.1016/j.vetmic.2009.04.011.
[8] Mamun MM, Parvej MS, Ahamed S, Hassan J, Nazir KHMNH et al. (2016) Prevalence and Characterization of Shigatoxigenic Escherichia coli in Broiler Birds in Mymensingh. Bangl. J. Vet. Med. 14: 5-8.

[9] Hussein HS, Sakuma T (2005) Prevalence of Shiga toxin producing Escherichia coli in dairy cattle and their products. J Dairy Sci.88 (2): 450-465.

[10] Karch H, Tarr PI, Bielaszewska M (2005) Enterohaemorrhagic Escherichia coli in human medicine. International Journal of Medical Microbiology. 295 (6-7): 405-418. doi:10.1016/j.ijmm.2005.06.009.

[11] Hussain MM, Glass RJ, Khan MR (1982) Antibiotics used in a rural community in Bangladesh. Int. J. Epidemiol. 11: 402405.

[12] Schroeder CM, Zhao C, Debroy C, Torcolini J, Zhao J et al. (2002) Antimicrobial resistance of Escherichia coli 0157 isolated from humans, cattle, swine and food. Appl. Environ. Microbiol. 68(2): 576-581. doi: 10.1128/AEM.68.2.576-581.

[13] Ashikuzzaman M, Shahriyar S, Lijon MB, Rahman MA, Hassan MM et al. (2015) An investigation on heavy metal tolerance properties of bacterial isolated from textile effluent. Journal of Biodiversity \& Environmental Sciences.7 (6): 6271.

[14] Eklund C, Lankford (1967) Laboratory Manual for General Microbiology. New Jersy: Prentice-Hall, Inc., Englewood Cliffs, pp. 1-551.

[15] Society of American Bacteriologists (SAB) (1957) Manual of Microbiological Methods. New York, London: McGraw-Hill Book Co. Inc., pp.315.

[16] Collins CH, Lyne MP (1984) Microbiological Methods. 5th ed. Butterworth and Co. Ltd., pp. 56-113.

[17] Claus GW (1995) Understanding Microbes A Laboratory Text Book for Microbiology. USA: WH Freeman and Company, pp. 547.

[18] Bryan H (1950) Manual of Methods for Pure Culture Study of Bacteria. 12: 1-10.

[19] Guan S, Xu R, Chen S, Odumeru J, Gyles C (2002) Development of a procedure for discriminating among Escherichia coli isolates from animal and human sources. Appl. Environ. Microbiol. 68 (6):2690-2698. doi: 10.1128/AEM.68.6.2690-2698.

[20] CLSI (2013) Clinical and Laboratory Standards Institute (CLSI) Guidelines.27: Wane, PA, USA. 
[21] Sultana S, Islam MA, Khatun MM, Nasrin S (2012) Multidrug Resistant Bacteria in the Respiratory Tract of Apparently Healthy Quails. Microbes and Health. 1 (2): 46-49.

[22] Hossain MT, Siddique MP, Hossain FMA, Zinnah MA, Hossain MM et al. (2008) Isolation, Identification, Toxin Profile and Antibiogram of Escherichia coli Isolated from Broilers and Layers in Mymensingh District of Bangladesh. Bangl. J. Vet. Med. 6 (1): 01-05.

[23] Akond MA, Alam S, Hassan SMR, Shirin M (2009) Antibiotic Resistance of Escherichia Coli Isolated From Poultry and Poultry Environment of Bangladesh. Internet Journal of Food Safety. 11: 19-23.

[24] Ferdousa TA, Hossain KMM, Kabira SML, Amina MM (2012) Characterization of Escherichia coli isolates obtained from washing and rinsed water of broilers in pluck shops at Sreepur of Gazipur district in Bangladesh. Scientific Journal of Microbiology. 1 (5): 126-132.

[25] Buchanan RE, Gibbons NE (1974) Bergey's Manual of Determinative Bacteriology. 8th ed. Williams \& Wilkins Co., Baltimore, pp. 1246.

[26] Margot H, Cernela N, Iversen C, Zweifel C, Stephan R (2013) Evaluation of seven different commercially available real-time PCR assays for detection of Shiga toxin 1 and 2 gene subtypes. J. Food Prot. 76 (5):871-3. doi: 10.4315/0362028X.JFP-12-365

[27] Kawano K, Ono H, Iwashita O, Kurogi M, Haga T et al.
(2012) Relationship between Stx genotype and Stx2 Expression Level in Shiga 96 Toxin-Producing Escherichia coli O157 strains. Japanese Journal of Infectious Disease. 65: 322-5.

[28] Magwedere K, Dang HA, Mills EW, Cutter CN, Roberts EL et al. (2013) Incidence of Shiga toxin-producing Escherichia coli strains in beef, pork, chicken, deer, boar, bison, and rabbit retail meat. Journal of Veterinary Diagnostic Investigation. 25: 254-8.

[29] Parma YR, Chacana PA, LucchesiPM, Roge A, Granobles VCV (2012) Detection of Shiga toxin producing Escherichia coli by sandwich enzyme-linked immune sorbent assay using chicken egg yolk IgY antibodies. Front. Cell Infect. Microbiol. 18: 84 .

[30] Nazir KHMNH (2004) Molecular base of diversified E. coli isolates potentiating antibiotics resistant and comprising epidemiology. MS Thesis, Bangladesh Agriculture University, Mymensingh, Bangladesh.

[31] Jeyasanta IK, Aiyamperumal V, Patterson J (2012) Prevalence of antibiotic resistance Escherichia coli in sea foods of Tuticorin coast, South-Eastern India. Advan. Biol. Res. 6(2):70-77. doi: 10.5829/idosi.abr.2012.6.2.6475

[32] Ozaki H, Esaki H, Takemoto K, Ikeda A, Nakatani Y et al. (2011)Antimicrobial resistance in fecal Escherichia coli isolated from growing chickens on commercial broiler farms. J. Vet. Microbiol. 150(1-2):132-9. doi: 10.1016/j.vetmic.2010.12.020. 